\title{
Impact of resolving the diurnal cycle in an ocean-atmosphere GCM. Part 2: A diurnally coupled CGCM.
}

Article

Published Version

Bernie, D.J., Guilyardi, E., Madec, G., Slingo, J.M., Woolnough, S.J. and Cole, J. (2008) Impact of resolving the diurnal cycle in an ocean-atmosphere GCM. Part 2: A diurnally coupled CGCM. Climate Dynamics, 31 (7-8). pp. 909-925. ISSN 0930-7575 doi: https://doi.org/10.1007/s00382-0080429-z Available at https://centaur.reading.ac.uk/1198/

It is advisable to refer to the publisher's version if you intend to cite from the work. See Guidance on citing.

Published version at: http://dx.doi.org/10.1007/s00382-008-0429-z

To link to this article DOI: http://dx.doi.org/10.1007/s00382-008-0429-z

Publisher: Springer

All outputs in CentAUR are protected by Intellectual Property Rights law, including copyright law. Copyright and IPR is retained by the creators or other copyright holders. Terms and conditions for use of this material are defined in the End User Agreement.

www.reading.ac.uk/centaur 
Central Archive at the University of Reading

Reading's research outputs online 


\title{
Impact of resolving the diurnal cycle in an ocean-atmosphere GCM. Part 2: A diurnally coupled CGCM
}

\author{
D. J. Bernie · E. Guilyardi · G. Madec $\cdot$ J. M. Slingo $~$ \\ S. J. Woolnough $\cdot$ J. Cole
}

Received: 13 July 2007/ Accepted: 23 May 2008/Published online: 28 June 2008

(C) British Crown Copyright 2008

\begin{abstract}
Coupled ocean atmosphere general circulation models (GCM) are typically coupled once every $24 \mathrm{~h}$, excluding the diurnal cycle from the upper ocean. Previous studies attempting to examine the role of the diurnal cycle of the upper ocean and particularly of diurnal SST variability have used models unable to resolve the processes of interest. In part 1 of this study a high vertical resolution ocean GCM configuration with modified physics was developed that could resolve the diurnal cycle in the upper ocean. In this study it is coupled every $3 \mathrm{~h}$ to atmospheric GCM to examine the sensitivity of the mean climate simulation and aspects of its variability to the inclusion of diurnal ocean-atmosphere coupling.

The inclusion of the diurnal cycle leads to a tropics wide increase in mean sea surface temperature (SST), with the strongest signal being across the equatorial Pacific where the warming increases from $0.2^{\circ} \mathrm{C}$ in the central and western Pacific to over $0.3^{\circ} \mathrm{C}$ in the eastern equatorial Pacific. Much of this warming is shown to be a direct consequence of the rectification of daily mean SST by the diurnal variability of SST. The warming of the equatorial Pacific leads to a redistribution of precipitation from the Inter tropical convergence zone (ITCZ) toward the equator. In the western Pacific there is an increase in precipitation between
\end{abstract}

D. J. Bernie $(\square)$

Met Office Hadley Centre, Fitzroy road, EX1 3PB Exeter, UK

e-mail: dan.bernie@metoffice.gov.uk

D. J. Bernie · E. Guilyardi · J. M. Slingo ·

S. J. Woolnough $\cdot$ J. Cole

National Centre for Atmospheric Science-Climate, Department

of Meteorology, University of Reading, Reading, UK

D. J. Bernie · E. Guilyardi · G. Madec

Laboratoire d'Océanographie et du Climat: Expérimentation

et Approches, Numériques, IPSL, Paris, France
Papa new guinea and $170^{\circ} \mathrm{E}$ of up to $1.2 \mathrm{~mm} / \mathrm{day}$, improving the simulation compared to climatology.

Pacific sub tropical cells are increased in strength by about $10 \%$, in line with results of part 1 of this study, due to the modification of the exchange of momentum between the equatorially divergent Ekman currents and the geostropic convergence at depth, effectively increasing the dynamical response of the tropical Pacific to zonal wind stresses.

During the spring relaxation of the Pacific trade winds, a large diurnal cycle of SST increases the seasonal warming of the equatorial Pacific. When the trade winds then re-intensify, the increase in the dynamical response of the ocean leads to a stronger equatorial upwelling. These two processes both lead to stronger seasonal basin scale feedbacks in the coupled system, increasing the strength of the seasonal cycle of the tropical Pacific sector by around $10 \%$. This means that the diurnal cycle in the upper ocean plays a part in the coupled feedbacks between ocean and atmosphere that maintain the basic state and the timing of the seasonal cycle of SST and trade winds in the tropical Pacific.

The Madden-Julian Oscillation (MJO) is examined by use of a large scale MJO index, lag correlations and composites of events. The inclusion of the diurnal cycle leads to a reduction in overall MJO activity. Precipitation composites show that the MJO is stronger and more coherent when the diurnal cycle of coupling is resolved, with the propagation and different phases being far more distinct both locally and to larger lead times across the tropical Indo-Pacific. Part one of this study showed that that diurnal variability of SST is modulated by the MJO and therefore increases the intraseasonal SST response to the different phases of the MJO. Precipitation-based composites of SST variability confirm this increase in the coupled simulations. It is argued that including this has increased 
the thermodynamical coupling of the ocean and atmosphere on the timescale of the MJO (20-100 days), accounting for the improvement in the MJO strength and coherency seen in composites of precipitation and SST.

These results show that the diurnal cycle of oceanatmosphere interaction has profound impact on a range of up-scale variability in the tropical climate and as such, it is an important feature of the modelled climate system which is currently either neglected or poorly resolved in state of the art coupled models.

\section{Introduction}

\subsection{Background}

Due to the tight coupling of ocean and atmosphere, scale interactions, i.e. the influence of small spatial scales and high frequency temporal scales on the large scale, low frequency variability of the climate system and vice versa, play an important role in the tropical climate (Slingo et al. 2003). The Madden-Julian Oscillation (MJO) exemplifies such scale interactions at work. Within the 'active' phase of the MJO, satellite data have revealed interacting convective activity over a range of scales from individual clouds, to cloud clusters associated with synoptic-scale disturbances, to super clusters or ensembles of clusters (Nakazawa 1988; Lau et al. 2002). Additionally, the MJO itself is also involved in scale interactions with various other phenomena through which it exerts a broad and profound effect on the climate system. Annamalai and Slingo (2001) show the link between the MJO and active/break phases of the Asian summer monsoon, while Lawrence and Webster (2001) demonstrate the MJO's relationship to the inter-annual variability of the monsoon. Furthermore, surface westerly wind bursts associated with the MJO over the western Pacific can also trigger oceanic down-welling Kelvin waves which are important in determining the strength and timing of some El Niño events (McPhaden 1999; Kessler and Kleeman 2000; Lengaigne et al. 2004).

These scale interactions, as well as the forcing of atmospheric Rossby waves by the divergent outflow from tropical convection which affects weather in the extra tropics, mean that the ability of numerical models to accurately represent the MJO is an important challenge for weather and climate scientists. An accurate representation of the MJO will ultimately require improvements in many different aspects of the MJO from the coupling of convection and atmospheric dynamics to the interaction of the atmosphere with the upper ocean (Slingo et al. 2006).

The importance of ocean-atmosphere coupling in the MJO has been demonstrated in numerous studies.
Observational studies such as Hendon and Glick (1997), Shinoda et al. (1998), and Woolnough et al. (2000) show coherent variations of sea surface temperature (SST) and convection as the MJO propagates east, showing that the atmosphere is able to force the ocean at these time scales. Additionally Woolnough et al. (2001) have shown, with idealised aqua-planet experiments, that eastward propagating SST perturbations of the size and spatial extent associated with the MJO, are able to drive atmospheric convection on the temporal and spatial scale of the MJO. These studies demonstrate between them the ability of the ocean and atmosphere to force one another on the time scale of the MJO, showing potential for the MJO to be strongly modified by ocean-atmosphere interaction.

The importance of ocean-atmosphere coupling to the MJO is also supported by its poor representation in atmosphere only GCM (AGCM) (Slingo and co-authors 1996) and its improvement when the AGCM is coupled to either a mixed layer model (Waliser et al. 1999) or fully dynamical ocean GCM (OGCM) (Inness and Slingo 2003; Lin et al. 2006; Rajendran and Kitoh 2006; Zhang et al. 2006). However, though there is a broad consensus that oceanatmosphere coupling is important to the MJO (Slingo et al. 2006), the improvements in its representation due to ocean-atmosphere coupling have often been limited and have raised other issues such as the significance of the basic state, particularly the low level winds in the western Pacific (Inness et al. 2003). Inness and Slingo (2003) also highlight that, though the coupled ocean-atmosphere GCM (CGCM) they examine produces realistic magnitudes of surface flux variability associated with the MJO, the SST response is far smaller than observed suggesting that this is due to shortcomings in the representation of the upper ocean.

Observational studies from TOGA-COARE (Webster and Lukas 1992) show evidence of large diurnal variability of SST (Anderson et al. 1996) and an associated diurnal cycle of cumulus congestus convection in the western Pacific (Johnson et al. 1999) during the convectively suppressed phase of the MJO. Slingo et al. (2003) cite the implied ability of the ocean and atmosphere to force one another even at diurnal time scales as providing potential for a feedback on the MJO. The moistening of the free troposphere by this shallow cumulus during the quiescent phase of the MJO may act to 'pre-condition' the atmosphere for the deep convection of the active phase, setting a time scale for the MJO [c.f. the recharge discharge hypothesis of Blade and Hartmann (1993)]. The subsequent study of Bernie et al. (2005) (B05 from herein) used an idealised one dimensional mixed layer model to show that the direct rectification of the diurnal cycle of SST (Dsst) onto the intraseasonal SST response to the MJO accounts for about a third of its variability in the western Pacific 
during the TOGA-COARE period. They propose that the diurnal cycle (specifically the lack of a properly resolved diurnal cycle) is the cause of the small SST response to the MJO noted by Inness and Slingo (2003). They further show that a vertical resolution of around $1 \mathrm{~m}$ is needed in the near surface to resolve Dsst and that therefore current state of the art CGCM are unable to properly resolve the diurnal cycle of ocean-atmosphere interaction. This was then confirmed by the first part of this study, Bernie et al. (2007) (B07 from herein), in which a high vertical resolution OGCM with modified ocean physics was used to examine the diurnal cycle in the upper ocean. In ocean-only experiments, the Dsst in the Indo-Pacific warm pool was shown to be modulated by the different phases of the MJO, as in observations, and this modulation of Dsst increased the magnitude of the intraseasonal SST response to the MJO in agreement with the propositions of Shinoda and Hendon (1998) and B05.

B07 also demonstrate that the diurnal cycle in the upper ocean has an impact on the dynamical behaviour of the tropical Pacific. Its inclusion lead to a modification of the exchange of momentum between the equatorially divergent Ekman layer and the convergent geostrophic currents below. The impact of this increased 'separation' of meridional currents lead to sub tropical cells (STC) which were around $10 \%$ stronger with the inclusion of the diurnal cycle. This result has potentially important implications for the modelling of the Walker circulation-warm pool/cold tongue complex in the Pacific. However, though the constrained nature of the experiments in B07 was useful for examining ocean-only mechanisms, the climate impacts of the dynamical sensitivity of the tropical Pacific to the diurnal cycle can only possibly be examined in coupled simulations including full atmospheric feedbacks.

A recent study of Danabasoglu et al. (2006) (D06 from herein) previously made a preliminary attempt to examine the impact of Dsst in a coupled model. By their own admission, D06 are unable to adequately resolve Dsst due to the vertical ocean resolution of their model and they also simply parameterise the diurnal cycle of ocean-atmosphere coupling. In addition D06 do not identify or consider the effect of the diurnal variability on ocean dynamics. Moreover the focus of D06 is more on longer term equilibrium and mean state than seasonal and intraseasonal variability. Also the GFDL CM2.0 and CM2.1, Griffies et al. (2005), also include an explicit diurnal coupling of the ocean and atmosphere, but as in D06 the near surface vertical resolution of the ocean in both $(5 \mathrm{~m})$ is too large to be able to resolve the diurnal variability of mixed layer of SST. As a consequence the present study is unique in its ability to resolve the diurnal variability of the mixed layer and of ocean-atmosphere interaction.

\subsection{Scope of present study}

The aim of this paper is to examine the impact of the mechanisms highlighted in B07 on the diurnal to seasonal variability of the coupled system, which are a consequence of resolving the diurnal cycle in the upper ocean and of ocean-atmosphere interaction. A coupled model is described which incorporates the modified high vertical resolution OGCM configuration in B07. This is then used to examine the impact of the resolved diurnal cycle of ocean-atmosphere coupling on the mean state and seasonality of the tropics. The effect of the dynamical impact of the diurnal cycle in the Pacific is a particular focus in this section. The MJO is then examined to see what impact the increased strength of coupling argued for in B07 has on the strength and coherence of its simulation.

The structure of the remainder of the paper is as follows: Sect. 2 outlines the methodology used in this study including details of the model used, the experimental design and the analysis techniques used. Sections 3 and 4 examine the dynamical impact of the diurnal cycle by examination of the mean state and seasonal cycle of the tropical Pacific respectively. Section 5 then examines the impact of the diurnal cycle on the MJO through indices, lag correlations and composite events. Discussions and conclusions are then presented in Sect. 6.

\section{Methodology}

\subsection{The HadOPA coupled ocean-atmosphere GCM}

The CGCM that is used throughout this study is HadOPA ${ }^{1}$ which consists of Hadley centre Atmospheric Model version 3 (HadAM3) developed at the UK Met Office (Pope et al. 2001), coupled to the French OPA OGCM (Madec et al. 1998). The coupling between the two components is performed using the Ocean Atmosphere Sea Ice Soil (OASIS3) coupling software developed at CERFACS (Valcke et al. 2004). HadOPA has previously been shown to have a good representation of the tropical climate and its variability, particularly the MJO (Inness et al. 2001) and El Niño variability (Lengaigne et al. 2004; Guilyardi 2006).

OPA is based on the primitive equations (including potential temperature, salinity and horizontal currents), solved by finite difference schemes. Vertical mixing is modelled with a prognostic turbulent kinetic energy (TKE) scheme (Blanke and Delecluse 1993). A non-penetrative convective adjustment scheme is used to remove instability in the water column (Madec et al. 1991). Lateral mixing is

\footnotetext{
${ }^{1}$ See http://www.met.rdg.ac.uk/ ericg/hadopa_project.html for more details
} 
of a Laplacian type (Lengaigne et al. 2003) and acts along isopycnals. The Gent and McWilliams (1990) eddy induced velocity parameterisation is also used. The configuration used throughout this study is ORCA2 which has a zonal resolution of $2^{\circ}$ while the meridional resolution varies from $2^{\circ}$ at high latitudes to $0.5^{\circ}$ at low latitudes to better resolve the equatorial wave guide. As the focus of the paper is tropical, sea-ice is prescribed as a monthly climatology of ice concentration from Chapman and Walsh (1991). A 90 min time step has been chosen so that a 3 hourly flux resolution is coincident with time steps. A linear free surface formulation is used as described in Roullet and Madec (2000). The choice of a linear free surface scheme, rather than non-linear, is a pragmatic one. When using a the non-linear scheme the variation of free surface height it is included as a variation of thickness of the top model layer. The initial implementation of this scheme in OPA was in a $10 \mathrm{~m}$ near surface vertical resolution configuration, however in the $1 \mathrm{~m}$ vertical resolution configuration used here (developed in B07) the thickness of the top model layer would no doubt vanish or become negative as global sea surface height variations are on the order of a few meters. The linear solution includes all the dynamical effects of the free surface height variation, which are little affected by the linearisation, but essentially assumes a constant volume and hence levels thickness thereby avoiding the problem of vanishing level thickness. It is worth noting that while this paper was in review a nonlinear free surface solution that avoids the problem of vanishing surface layers has become available in OPA (and the MITgcm) and future work will use this solution. The full solution avoids the vanishing surface layer by distributing the variation in ocean height over the depth of the ocean grid rather than the surface layer, as proposed as a possibility in Roullet and Madec (2000). Finally on the free surface, it is of note that the underlying assumptions of the linearisation become less accurate at these higher resolutions and the numerical implications of this have not been investigated here as future plans will concentrate on the non-linear free surface implementation.

In B07 a configuration of ORCA2 was developed to resolve the diurnal cycle. A number of refinements to the standard configuration of ORCA2 were needed to achieve this. Firstly the vertical resolution is increased to $1 \mathrm{~m}$ throughout the upper $100 \mathrm{~m}$ of the ocean following the findings of B05. This is achieved by increasing the number of vertical levels by a factor of ten producing a total of 301 levels. By taking this approach of increasing the number of levels, rather than changing the relative vertical distribution of levels, the bathymetry is unchanged, thereby allowing meaningful comparisons with the standard vertical resolution configuration. Though no such comparison is presented in this paper, details can be found in Bernie
(2006). In addition to the increased vertical resolution, the advection scheme is changed to a more stable total variance dissipation (TVD) scheme in order to reduce the near surface background vertical diffusivity towards observed values. Finally a parametrisation of the effects of surface wave breaking on near surface turbulence, developed by Mellor and Blumberg (2004), is included to produce more efficient turbulent mixing in moderate to high wind conditions. Full details of these modifications and their validation can be found in $\mathrm{B} 07$.

HadAM3 is a hydrostatic model on the Arakawa B-grid with a horizontal resolution of $2.5^{\circ}$ in latitude by $3.75^{\circ}$ in longitude. The vertical co-ordinates are hybrid eta giving a transform from pure terrain following sigma co-ordinates near the earth's surface to pure pressure in the stratosphere. Dry and moist convection are parameterised by a mass flux scheme closed on surface buoyancy following Gregory and Rowntree (1990). The version used here is described in detail in Pope et al. (2001) with the exception of the vertical resolution which has been increased from 19 levels to 30 levels improving the resolution in the mid troposphere from around 100 to $50 \mathrm{hPa}$ to better resolve tropical mid level convection as done by Inness et al. (2001) who show that this improves the simulation of the MJO in atmosphere-only integrations of HadAM3. This increased vertical resolution is done such that the height of the top and bottom 3 model levels are unchanged. This means that the flux calculations from the surface, which are sensitive to the height of the first atmospheric level (Fairall et al. 2003 and references therein), are still appropriate in this study. The land surface scheme is the Meteorological Office Surface Exchange Scheme (MOSES) of Cox et al. (1999).

It is worth detailing here that the atmospheric model HadAM3, including the land surface scheme, already includes some aspects of diurnal variability. There is a full representation of the seasonal and diurnal variations of incoming short wave radiation which interacts with the atmosphere throughout the diurnal cycle. The short wave radiation is then also able to produce a diurnal variability in surface temperature, via the land surface scheme, which can then act to destabilise the atmospheric boundary layer and trigger atmospheric convection (c.f. Yang and Slingo 2001) so there is already substantial diurnal variability in the atmospheric model. This is an important point as it demonstrates that the flux calculations and convection scheme used in the model are able to respond to diurnal surface heating making it appropriate for a study of diurnal ocean-atmosphere interaction. In the flux calculation the model SST that is used for the flux calculations is the temperature of the topmost model layer, in common with many OGCMs, and so it is representing the well mixed 'bulk' temperature of the ocean rather than the skin 
temperature. This assumption is not violated by the used of a $1 \mathrm{~m}$ vertical near surface ocean resolution as the skin is or the order of a few mm thick. Throughout the rest of this study the temperature of the top model layer $(0.5 \mathrm{~m}$ depth) will be referred to as the SST. It is reiterated that in previous studies the lack of diurnal coupling and the low vertical ocean resolution has excluded the diurnal cycle from the ocean and crucially completely removed any Dsst so that there is no possibility of a diurnal cycle of atmospheric convection over the oceans driven by surface heating.

\subsection{Experimental design}

The experimental aim is to perform two simulations that are identical in every way except that one resolves the diurnal cycle of ocean-atmosphere coupling and one does not. As detailed previously there is already a resolved diurnal cycle of the land surface and incoming short wave radiation and so the lack of diurnal coupling and sufficient resolution in the upper ocean excludes diurnal variability of the ocean mixed layer and resulting Dsst. Consequently the configuration of HadOPA used in this study incorporates the version of ORCA2 detailed in B07 which can resolve the diurnal cycle in the upper ocean. The first experiment has a coupling frequency of 1 day and is called High vertical resolution Daily Mean coupling (HDM). The other experiment, that resolves the diurnal cycle, has a coupling frequency of 3 hours and is called High vertical resolution Diurnal Cycle of coupling (HDC).

The initial conditions are the same for each experiment. The ocean component is spun up for 5 years from Levitus temperature and salinity at rest, with a daily varying climatology of surface fluxes from ERA-40 (Simmons and Gibson (2000) using a $40 \mathrm{~W} \mathrm{~m}^{-2} \mathrm{~K}^{-1}$ linear feedback on the SST towards that used in the ERA-40 reanalysis. This 5 years is referred to as the 'forced spin-up'. After the 'forced spin-up' the ocean is then coupled to the atmosphere with an atmospheric initial condition from 1st of January at the end of a 100 year simulation of a standard vertical resolution (31 level ocean) HadOPA integration. From this state a 'coupled spin-up' of 5 years is performed without the linear feedback on SST. Each experiment is then run for 50 years with no flux adjustment applied.

\section{Mean state}

Through its role in determining regions favourable to convection, SST is central to the behaviour of the tropical climate. Figure 1 shows the mean tropical SST used for the
AMIP project (Gates et al. 1998) (a) along with the 50 year mean SST from HDM (b), HDC (c) and the difference between HDC and HDM (d). The model captures the main observed features with a similar fidelity of other contemporary models. It is also clear that both experiments are more similar to each other than climatology with both containing many of the classic systematic biases of CGCM such as the warm waters of the west coast of Peru discussed by Mechoso and co-authors (1995) amongst others. The meridional extent of the Indo-Pacific warm pool, typically marked by the $28^{\circ} \mathrm{C}$ isotherm, is too small in both experiments and there is a general cool bias in both experiments compared to climatology. The comparison of HDC and HDM (Fig. 1d) shows that the inclusion of the diurnal cycle has an impact throughout the tropics. There is a climatological warming across the equatorial Pacific on the order of $0.2^{\circ} \mathrm{C}$ whilst the eastern Pacific shows a warming of up to $0.3^{\circ} \mathrm{C}$. It is worth reiterating that in regions where absolute SST is high $\left(>28^{\circ} \mathrm{C}\right.$, i.e. the western Pacific warm pool), a $0.2^{\circ} \mathrm{C}$ increase in SST can significantly affect atmospheric convection. There is also a warming across the Pacific at around $30^{\circ} \mathrm{N}$ which reaches $0.3^{\circ} \mathrm{C}$. The Atlantic and Indian oceans also show a warming signal though this will not be examined in the present paper as the focus is on the tropical Pacific and its variability, although it cannot be ruled out that such a change is significant.

As demonstrated by B07 (and references therein) the presence of Dsst increases the daily mean SST. Figure 1e shows the climatological magnitude of Dsst in HDC as seen by the atmosphere. If one assumes an idealised Dsst in which the SST linearly increases from a nocturnal minimum (the bulk mixed layer temperature) to a day time maximum, and then linearly decreases again, the "rectification" of the daily mean SST by Dsst could be expected to be on the order of half of the magnitude of Dsst. Considering this value, the signal in Fig. 1e implies that most of the warming across the equatorial Pacific $\left(10^{\circ} \mathrm{N}-10^{\circ} \mathrm{S}\right)$ in Fig. $1 \mathrm{~d}$ is likely associated with direct rectification by Dsst.

The change in precipitation that is brought about by the inclusion of the diurnal cycle in HDC is shown in Fig. 2. As with the SST, differences between HDC and HDM are small compared to the pervasive biases of the model. An error in both is a too zonal southern tropical convergence zone across the Pacific. Such a bias is common to many current CGCM, though the error here is not as serious as in some other models (Davey and co-authors 2002; Guilyardi 2006). In HDC this bias has been made worse with more equatorial convection over the cold tongue, due to the warming of SST by Dsst. This change in precipitation is apparently a redistribution of precipitation from the northern ITCZ toward the equator. In the western Pacific there is an increase in precipitation just south of the equator 
(a)

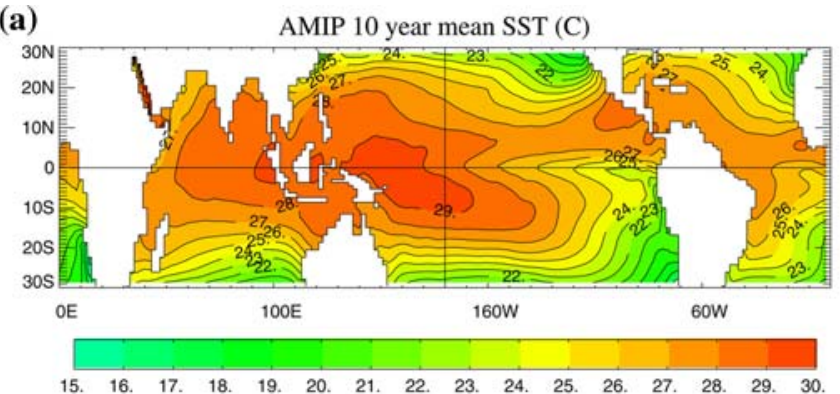

(b)

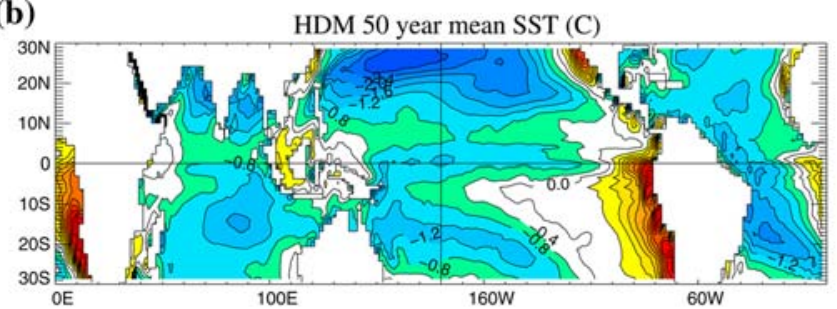

(c)

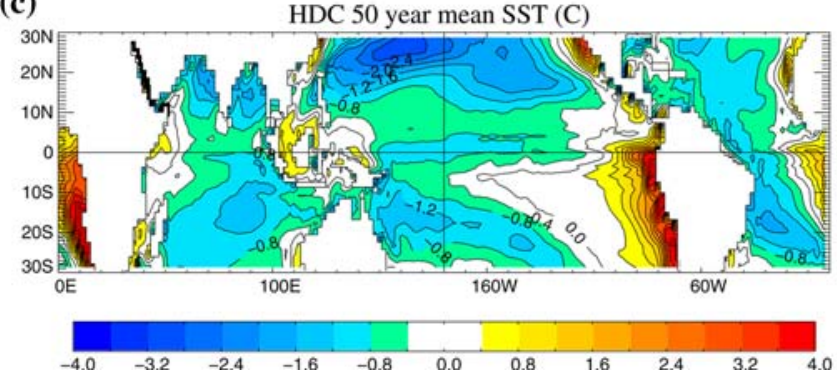

Fig. 1 Mean SST from AMIP project (Gates et al. 1998) (a), HDM (experiment with daily mean coupling) (b), HDC (experiment with a resolved diurnal cycle of coupling) (c), the difference between HDC

from the Papa New Guinea to around $170^{\circ} \mathrm{E}$ which is an improvement compared to climatology.

The changes in SST and precipitation are consistent with the changes in the surface wind stress shown in Fig. 3a. Over the western Pacific warm pool the light winds (Fig. 3b) allow a large climatological Dsst $\left(\sim 0.5^{\circ} \mathrm{C}\right.$, see Fig. 1e) which increases the mean SST (Fig. 1d). In response to this there is an increase in precipitation (Fig. 2) with an associated surface inflow producing an easterly anomaly extending to the east which is seen around the equator from $170^{\circ} \mathrm{E}$ to $150^{\circ} \mathrm{W}$ (Fig. 3a). This anomaly increases the magnitude of the basic state winds. As the magnitude of the wind stress is larger here than to the west (110 to $160^{\circ} \mathrm{E}$ ) Dsst is smaller in this region and results in only a small difference in mean SST between HDC and HDM (Fig. 1d). However, across the whole equatorial Indo-Pacific warm pool there is little change in wind stress, particularly over Indonesia. This nominal effect on the basic state will become important in the discussion of the MJO variability in the two experiments in Sect. 5. It should also be noted that though there are other regions which

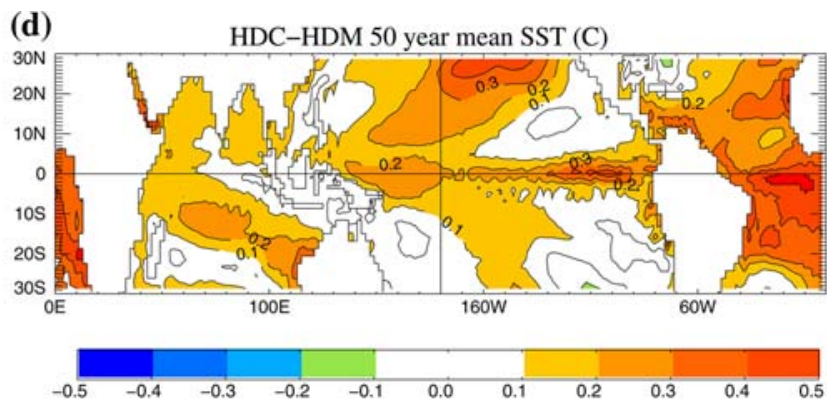

(e) HDC 50 year mean diurnal SST variability (C)

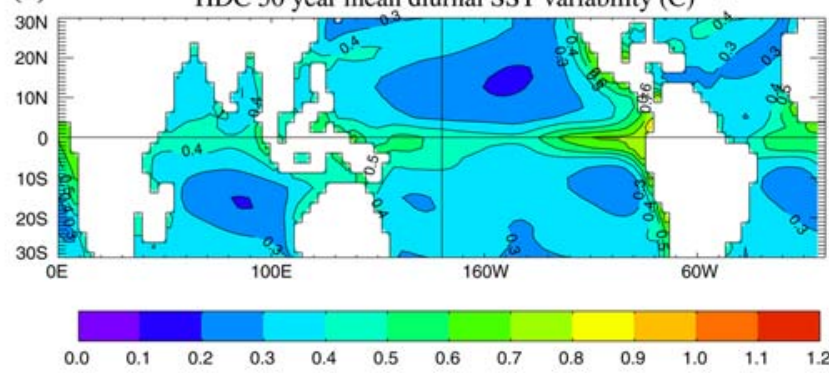

and HDM (d) and the mean diurnal SST variability (Dsst) from HDC (e). In e grid cells where there is any fraction of land on a coastal tile is shown as land due to a diagnostic problem

show larger changes in wind stress, for instance east of the date line from $10^{\circ} \mathrm{N}$ to $30^{\circ} \mathrm{N}$, these changes represent a much smaller relative change in the mean wind stress magnitude (Fig. 3b).

Though there are only small changes in the mean surface wind stress in HDC the dynamical structure of the tropical Pacific has been altered by the diurnal cycle in the same manner as the forced OGCM simulations in B07. The surface current differences show that there is an increase in the equatorial divergence of the surface currents (Fig. 4a) and there is an enhancement of the zonal currents of the Southern Equatorial Current (SEC) (Fig. 4b). As with the OGCM simulations in B07 this change is again due to stronger shallow meridional overturning cells, or "Ekman cells", in the tropical Pacific and a 'trapping' of momentum fluxes from wind stress near the surface. This can be seen easily in both an equatorial longitude-depth section of vertical velocity and the latitude-depth section of meridional stream function for the Pacific which are shown in Fig. 5. The figure shows that the equatorial upwelling and Ekman cells are roughly $10 \%$ stronger in HDC in line with B07. 

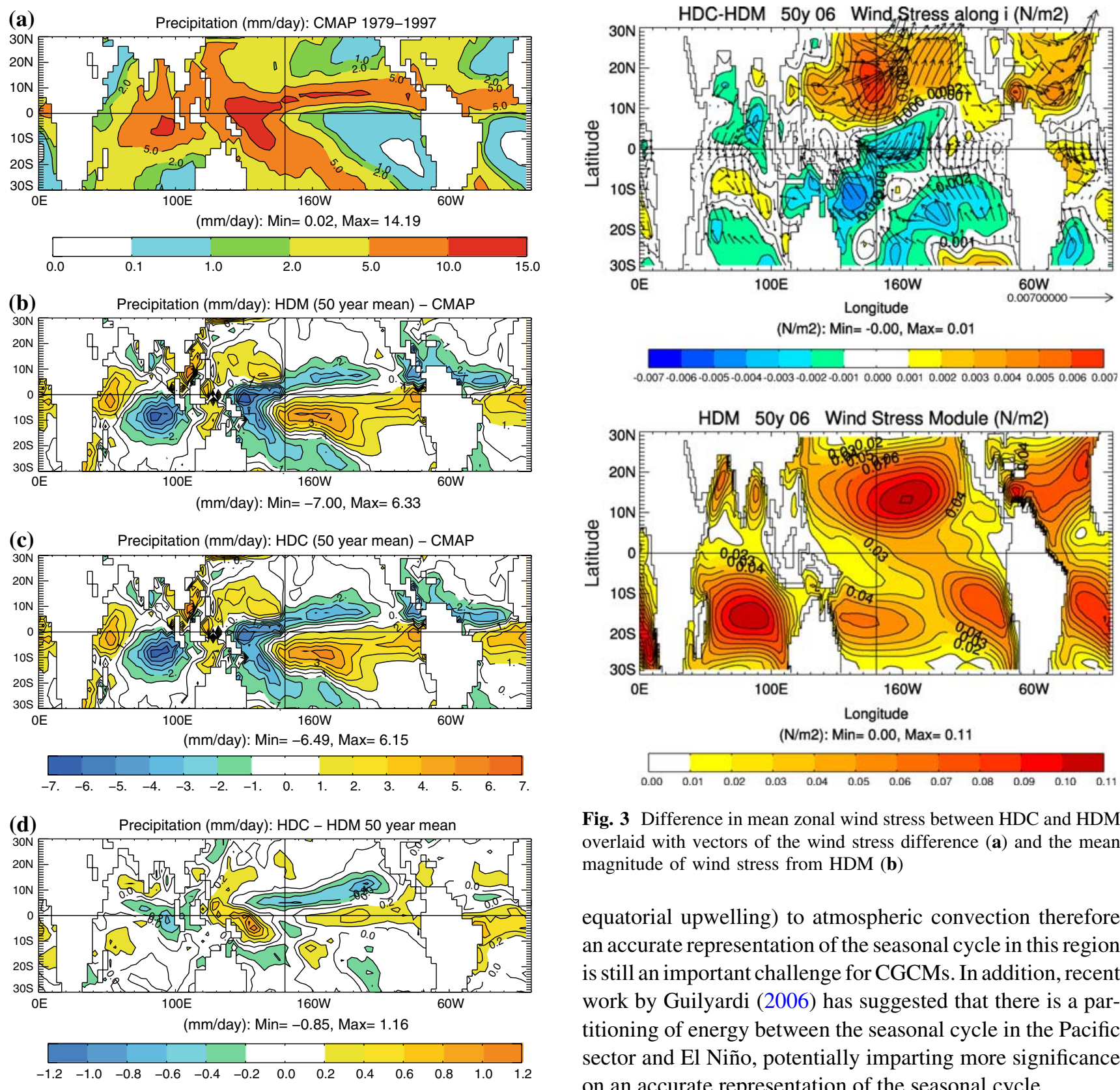

Fig. 2 Mean precipitation from CMAP (Xie and Arkin 1996) climatology (a), HDM (b), HDC (c) and the difference between HDC and HDM (d)

\section{Seasonal cycle}

The seasonality of the tropical Pacific climate is dominated by the large scale interaction of the atmosphere and ocean. This interaction is manifest in the interrelation of the atmospheric Walker circulation and the zonal SST gradient between the western Pacific warm pool and the cold tongue in the central and eastern equatorial regions. This coupling of atmosphere and ocean involves many different mechanisms in the climate system ranging from ocean dynamics (e.g.

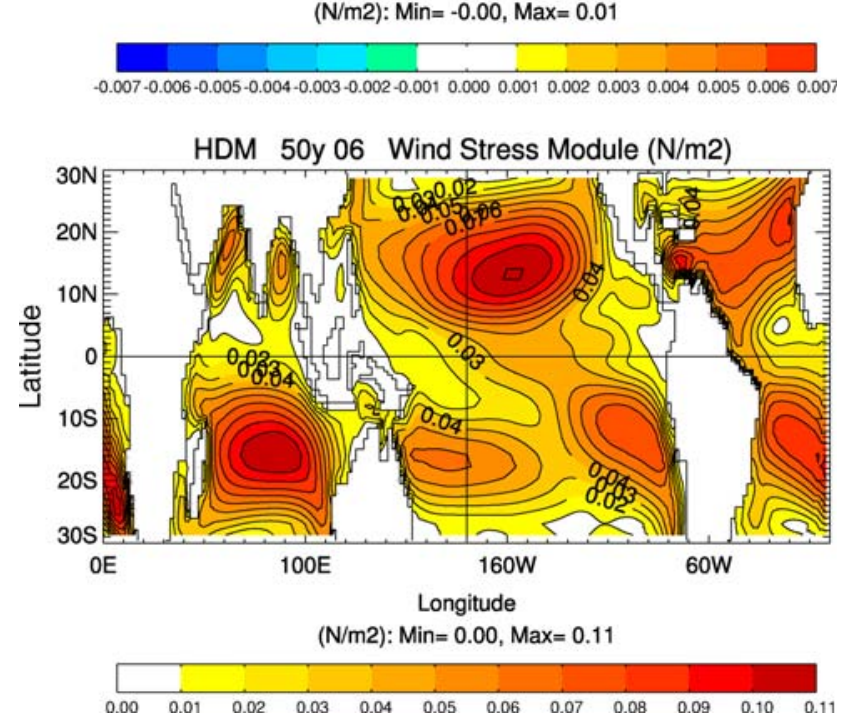

Fig. 3 Difference in mean zonal wind stress between HDC and HDM overlaid with vectors of the wind stress difference (a) and the mean magnitude of wind stress from HDM (b)

equatorial upwelling) to atmospheric convection therefore an accurate representation of the seasonal cycle in this region is still an important challenge for CGCMs. In addition, recent work by Guilyardi (2006) has suggested that there is a partitioning of energy between the seasonal cycle in the Pacific sector and El Niño, potentially imparting more significance on an accurate representation of the seasonal cycle.

In the first part of this study, B07 demonstrated that the diurnal cycle both has a significant impact on the dynamical behaviour of the tropical Pacific, and produces a large climatological Dsst (up to $0.6^{\circ} \mathrm{C}$ ) at low latitudes. These impacts of the diurnal cycle were examined in forced ocean-only simulations, with none of the complex atmospheric feedbacks manifested, so the possible impact of these effects on the seasonality of the coupled system could only be speculated. The impact of the diurnal cycle on the seasonal cycle of the coupled system is now examined with reference to these mechanisms.

Figure 6 shows the climatological seasonal cycle of SST along the equatorial Pacific for HDM (Fig. 6a) and the difference between HDC and HDM (Fig. 6b). The 
Fig. 4 Difference in the mean surface meridional (a) and zonal (b) currents between HDC and HDM

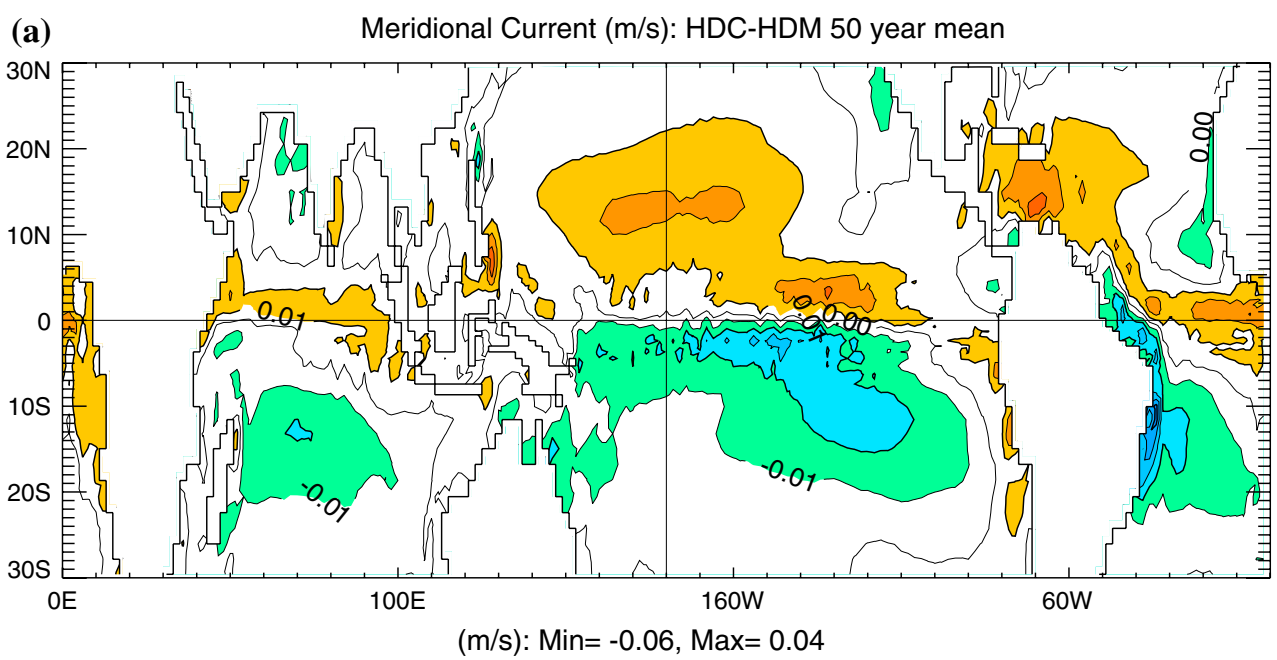

(b) Zonal Current (m/s): HDC-HDM 50 year mean

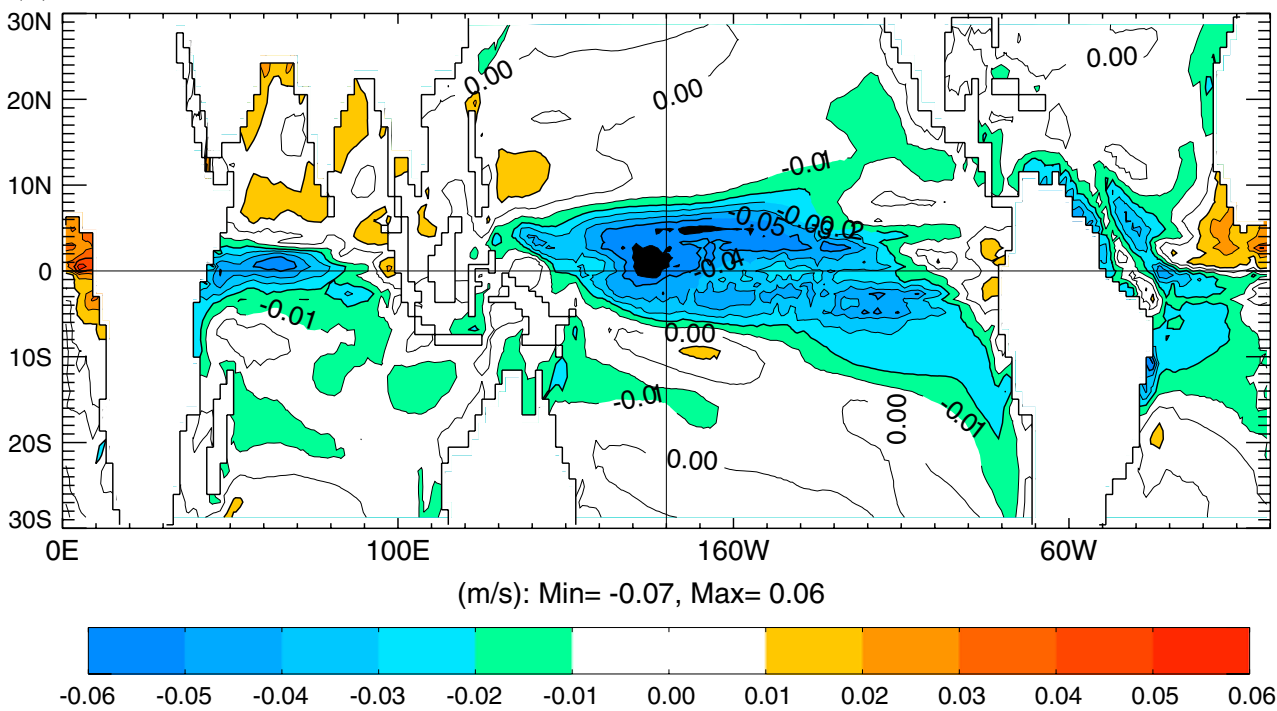

modelled seasonal cycle of SST is in good agreement with observations. Evident in (b) is the mean warming across the equator seen in Fig. 1(d). In the eastern Pacific HDC is warmer than HDM during the early spring (FebruaryMarch) when the annual cycle of SST is at its warmest. During this period the ITCZ is near the equator, the trade winds are relaxed and the upwelling of cold water is reduced. As the trades re-intensify (April-May), the upwelling strengthens and a cooling of SST begins. This cooling is stronger in HDC than HDM such that even though there is a mean warming on the equator in HDC (Fig. 1d), HDC is cooler than HDM by June. As the eastern Pacific SST starts to warm in the autumn (SeptemberNovember), HDC warms faster than HDM. The stronger warming of the eastern Pacific in HDC is then seen to propagate to the west.

Our explanation of Fig. 6 is the following. Starting in boreal spring and moving through the seasonal cycle, once the ITCZ moves north away from the equator and the trade winds re-intensify the stronger dynamical response of the upper ocean to the trade winds leads to a stronger and more rapid cooling of the cold tongue. The increased speed with which the cold tongue develops then leads to a more rapid development of the trade wind circulation (Fig. 6d). In addition to this there is the role of Dsst. During the northern winter as the trades begin to drop in intensity (November-May) and the cold tongue warms, the presence of diurnal SST variability (Fig. 6c) increases the warming. Once the trades start, the diurnal SST variability decreases and the daily mean SST drops accordingly. This means that the diurnal cycle in the upper ocean plays a part in the coupled feedbacks between ocean and atmosphere that maintain the basic state and the timing of the seasonal cycle of the tropical Pacific.

This is also shown by examining the rate and change of the season in HDC and HDM. Figure 7 shows the climatological seasonal cycle of SST in HDM (a) and HDC (b) as the rate of change in monthly mean equatorial SST from 


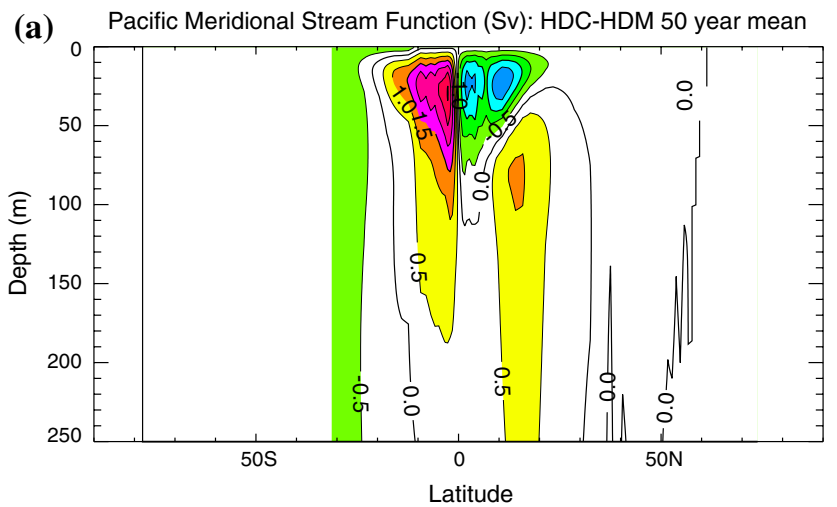

(Sv): Min $=-2.43, \operatorname{Max}=3.05$

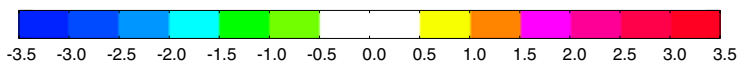

(c) Equatoiral Pacific Vertical Velocity (m/day): HDC-HDM 50 year mean

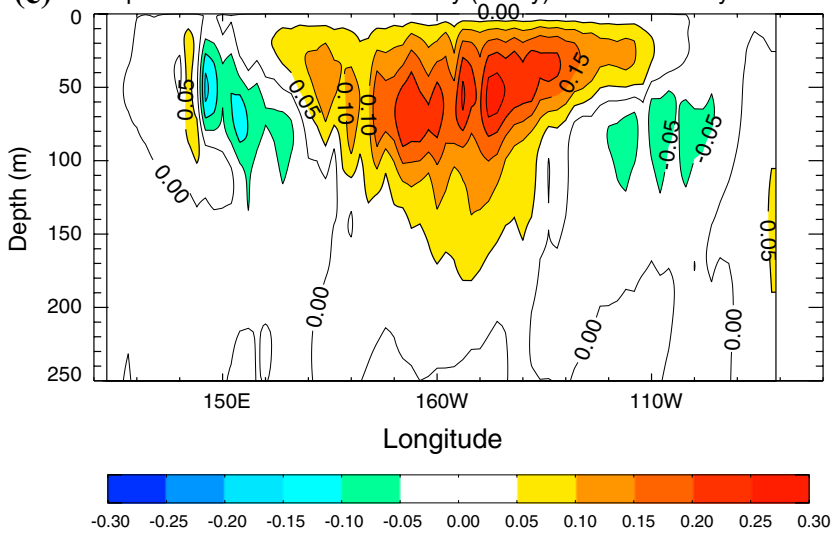

Fig. 5 Latitude-depth section of the difference in the Pacific meridional overturning stream function between HDC and HDM (a) with the absolute value in HDM (b) shown for reference. Rotation is anti-clockwise for positive values. Also shown is the longitude-depth

the previous month. This shows that during the spring relaxation of the trade winds, the warming of SST in the eastern Pacific is faster in HDC than in HDM due to Dsst. Once the trade winds re-intensify, the cooling from upwelling is stronger in HDC than in HDM. The change of timing of the seasonal cycle of SST in the eastern Pacific is thus enhanced by properly resolved diurnal coupling in HDC and the associated increase in seasonal Bejerknes feedbacks (Bjerknes 1969).

\section{Madden-Julian oscillation}

B07 demonstrated that the inclusion of the diurnal cycle in the upper ocean leads to an increase in the magnitude of the intraseasonal SST response to the MJO across the equatorial Indo-Pacific warm pool. It was argued that in a coupled framework a larger SST response for a given variation of surface fluxes may be able to force a stronger

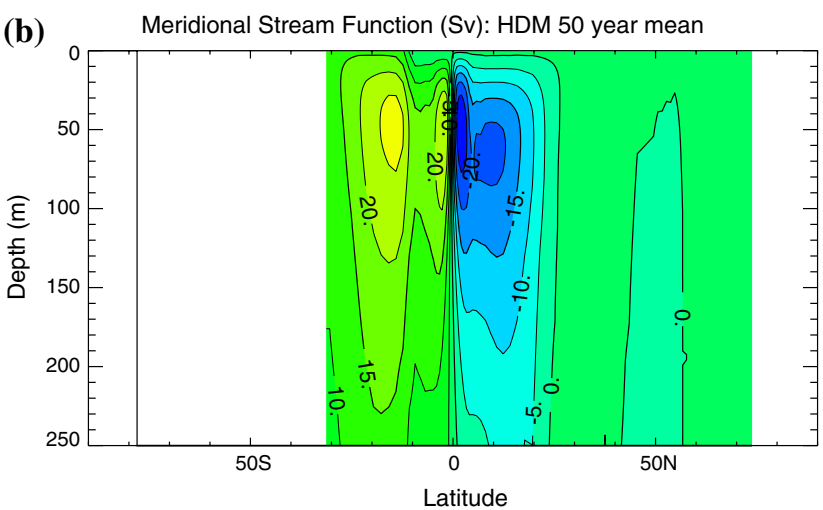

(Sv): $\operatorname{Min}=-28.86, \operatorname{Max}=27.01$

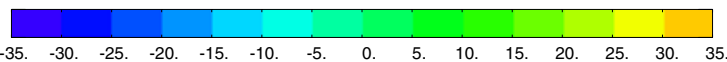

(d) Equatorial Pacific Vertical Velocity (m/day): HDM 50 year mean

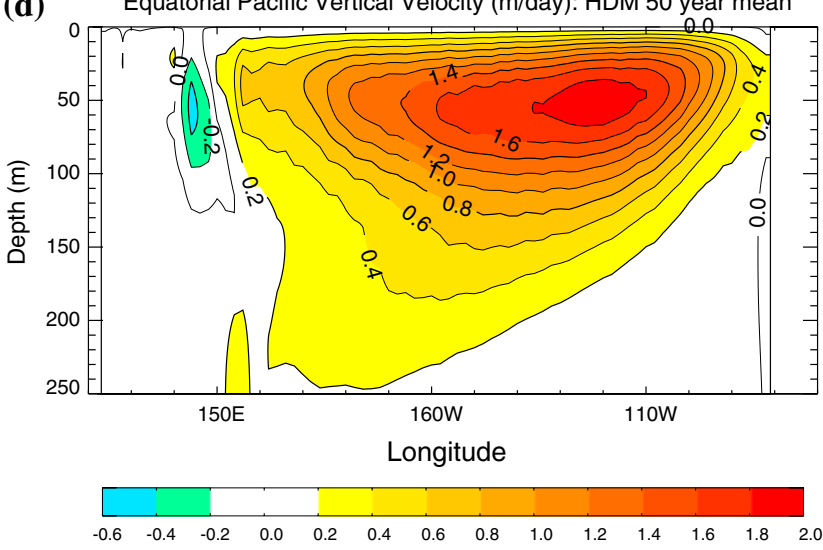

difference in equatorial vertical velocity between HDC and HDM across the Pacific (c) with the mean value in HDM (d) shown for reference

response from the atmosphere, thereby leading to an increase in the strength of the thermodynamical coupling between the ocean and atmosphere and potentially improve the representation of the MJO. This hypothesis is now examined using several diagnostics including large scale indices of MJO activity and composite MJO events.

A classical diagnostic of MJO activity is the MJO index as defined by Slingo et al. (1999). This is formed by first calculating the variance of daily values of zonal mean $200 \mathrm{hPa}$ zonal winds between $10^{\circ} \mathrm{S}$ and $10^{\circ} \mathrm{N}$. The result is then filtered using a 20-100 day band pass filter and a 100 day running mean is then applied to the variance. Slingo et al. (1999) show that this index of the intraseasonal variability of tropical upper level winds is well correlated with MJO activity in reanalysis. The mean values of this index given in Table 1 for HDM and HDC, as well as for ERA-40. The mean value in HDM is 1.90 whereas the mean of HDC is 1.67 , a reduction of $12 \%$, implying a decrease in mean MJO activity in HDC, which 
would seem to contaradict the hypothesis above. An explaination for this is proposed in the concluding discussions. Both experiments have lower than observed mean values of the index implying that the MJO is less active than in observations. Such a finding is common to many CGCM (Lin et al. 2006) though the global index of Slingo et al. (1999) should be used with caution as it mixes many intraseasonal signals.

Woolnough et al. (2000) used lag correlations of observed precipitation and SST to show that there is a coherent lag correlation between intraseasonally varying SST, atmospheric convection and the associated variability of surface fluxes across the Indian and western Pacific equatorial oceans. Woolnough et al. (2001) then used aqua planet experiments to show that SST anomalies of the size observed in association with the MJO are able to drive convective anomalies, demonstrating the possibility that the MJO is at least to some extent a coupled oceanatmosphere phenomena.

Lag correlation of precipitation with SST are shown for HDM and HDC in Fig. 8a and b, respectively, where both fields have been pre-processed with a 20-100 days Lanczos band-pass filter. The line of zero lag correlation of SST and the convective maxima in HDC is a average of around 3 days sooner when compared to HDM. An increase in the SST warming associated with the quiescent phase of the MJO by Dsst, (demonstrated in B07), would not necessarily lead to stronger lag correlation but would lead to a change in the timing of the transition from positive to negative anomaly. The explanation of this is that the SST maximum would be increased while the minimum remains the same. In the filtering process this would lead to the timing of the transition from positive to negative being shifted toward the warm phase, as seen in Fig. 8.

The range of scales of variability of tropical convection within the envelope of the MJO makes comparison of individual events difficult. A useful technique for examining the characteristics of the MJO is the approach of compositing over several events (Hendon and Salby 1994; Woolnough et al. 2000; Inness and Slingo 2003; Rajendran and Kitoh 2006). Here the technique first presented in Woolnough et al. (2000) and then modified by Inness and Slingo (2003) is used to identify individual events. The only difference in the compositing technique used here to that of Inness and Slingo (2003) is that here a different processing step is used to the final subjective removal of standing wave patterns that are identified as events. In the present study this step is replaced by a requirement that propagating disturbances must have a positive anomaly over the entire time where and when it is identified as a propagating event. This step produces similar results to the technique of Inness and Slingo (2003) whilst removing any subjective element in event selection.
Fig. 6 Climatological seasonal cycle across the equatorial Pacific: SST from HDM (a), the difference in SST between HDC and HDM (b), diurnal SST variability from HDC (c) and difference in zonal wind stress between HDC and HDM (d)

Composites are then performed for different variables from identified events to examine the coherence and propagation of the MJO.

Precipitation is used as a proxy for tropical convection to identify MJO events and composites made at 60, 90, 120 and $150^{\circ} \mathrm{E}$, to represent the different phases of the MJO from the Indian Ocean, its passage through the maritime continent and into the western Pacific warm pool. Only maxima between October and April are considered as the boreal summer MJO has been observed to have quite different characteristics by Annamalai and Slingo (2001).

The composites of precipitation from HDM and HDC are shown in Fig. 9. These composites show a consistent picture of a stronger and more coherent signal in the diurnally coupled HDC than HDM. At $60^{\circ} \mathrm{E}$ the positive signal remains strong extending to $120^{\circ} \mathrm{E}$ rather than rapidly dropping off as seen in HDM. The same is true with a stronger more organised signal in HDC for the composites based at $90^{\circ} \mathrm{E}$. There is also suggestion here that the preceding and subsequent negative phase of the MJO (the convectively suppressed phase) is stronger in HDC. This is also particularly evident in the composites at $120^{\circ} \mathrm{E}$ as the MJO starts to cross the maritime continent with a clear propagation of the negative phase out into the warm pool which is not seen in the HDM composite. By $150^{\circ} \mathrm{E}$ the HDM composite is starting to become weak with a standing wave pattern starting to appear to the east, while the HDC composite maintains a good propagation of both phases out into the warm pool, with suggestion of the previous and next events evident at large lead and lags respectively.

The hypothesis from B07 is that an increased SST response to the MJO (due to resolving Dsst) would lead to a stronger and more coherent MJO. Figure 9 clearly shows an improvement, but if the hypothesis of B07 is the cause of this, a stronger SST signal should be seen in the HDC composite. Figure 10 shows the precipitation-based SST composites for the two experiments. At $60^{\circ} \mathrm{E}$ it is hard to distinguish any evidence of an improvement in the propagation of the SST signal that is evident in the precipitation signal (Fig. 9). At $90^{\circ} \mathrm{E}$, however, differences are starting to become more apparent with a much stronger and more coherent signal in HDC which propagates out clearly toward the date line whereas the HDM composite decays more rapidly. The preceding and subsequent phases are also much stronger in HDC in line with results from the precipitation composites. In the 120 and $150^{\circ} \mathrm{E}$ composites the HDM signal is very weak indeed compared to the HDC whereas the signal remains strong and shows a coherent 
(a) Equatorial SST: HDM monthly climatology

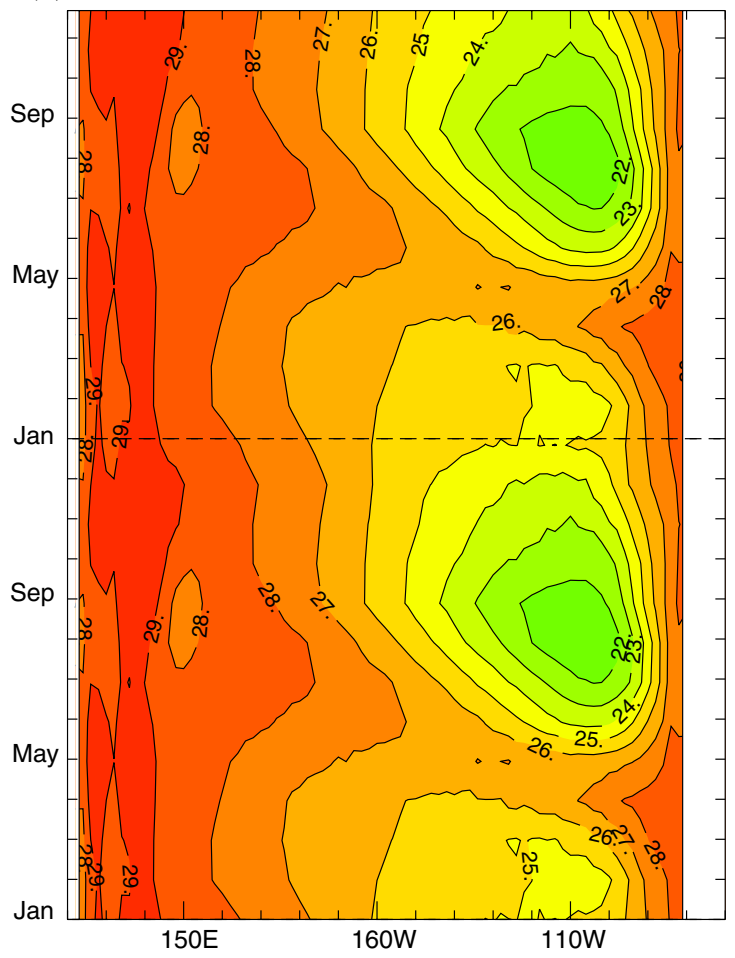

15. 16. 17. 18. 19. 20. 21. 22. 23. 24. 25. 26. 27. 28. $29 . \quad 30$

(c)

Diurnal SST variability (C):

HDC monthly climatology

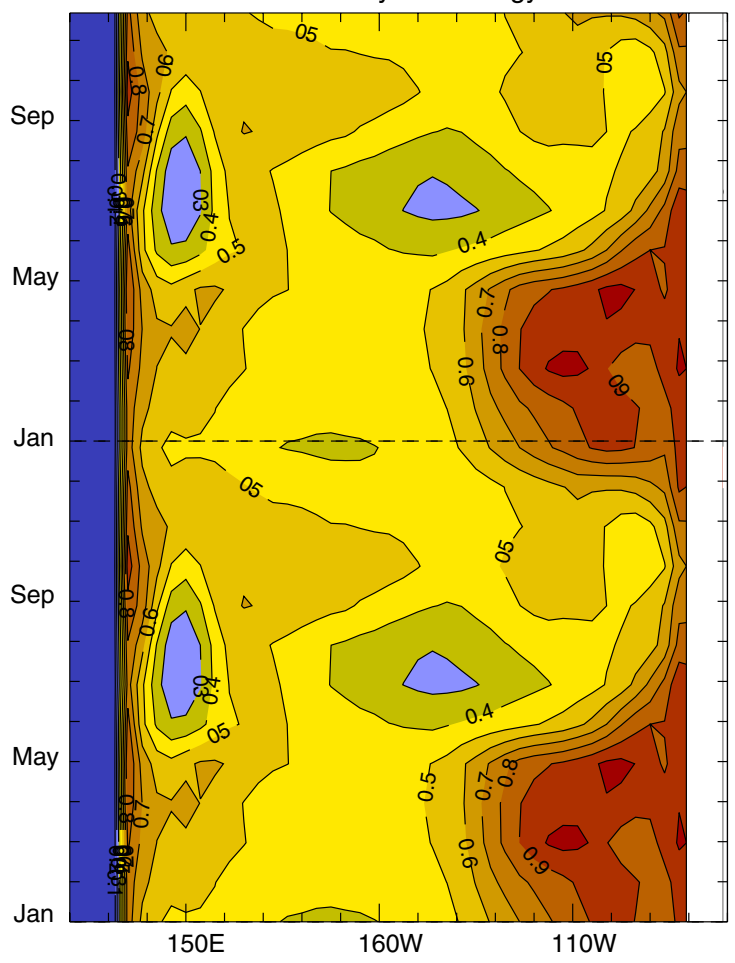

$\begin{array}{lllllllllll}0.0 & 0.1 & 0.2 & 0.3 & 0.4 & 0.5 & 0.6 & 0.7 & 0.8 & 0.9 & 1.0\end{array}$ (b) Equatorial SST: HDC-HDM monthly climatology

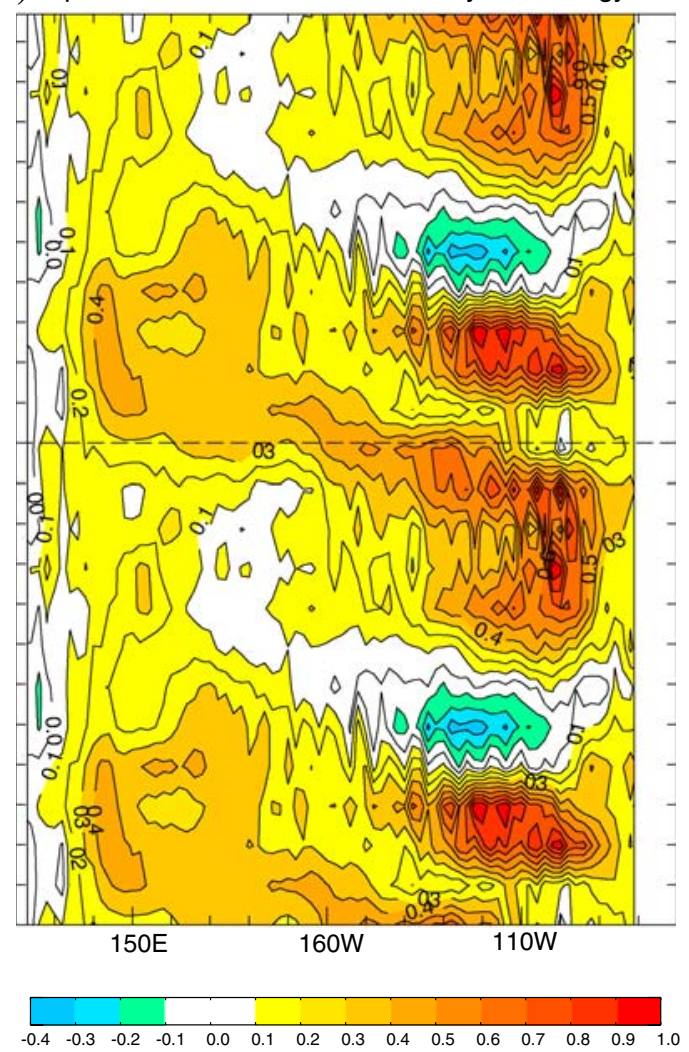

(d)

Equatorial Zonal Wind Stress (N/m2): HDC-HDM monthly climatology

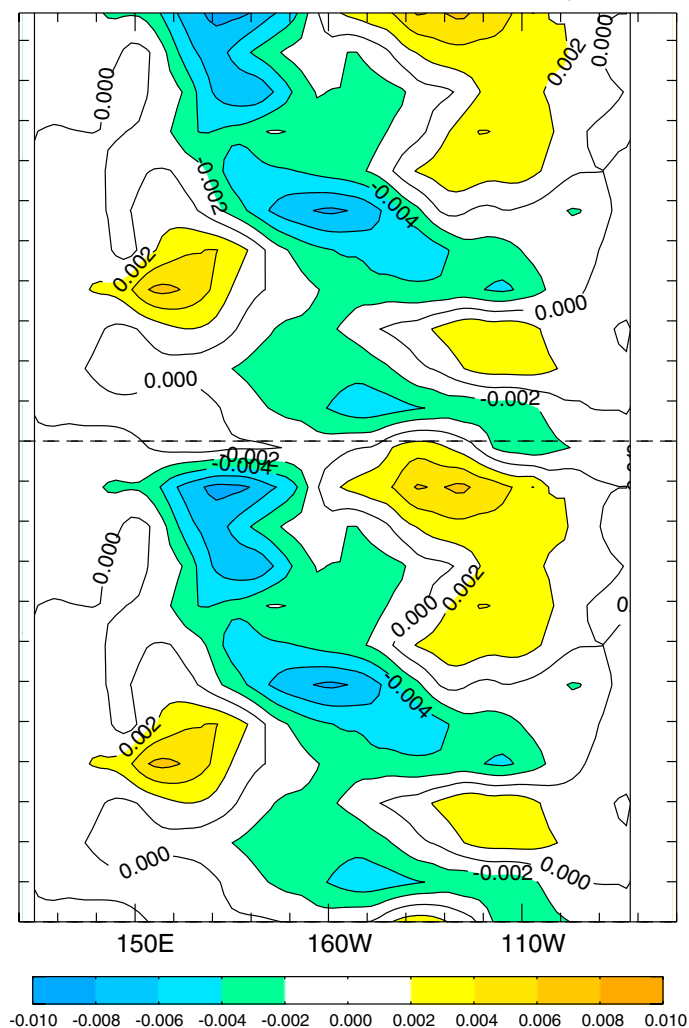




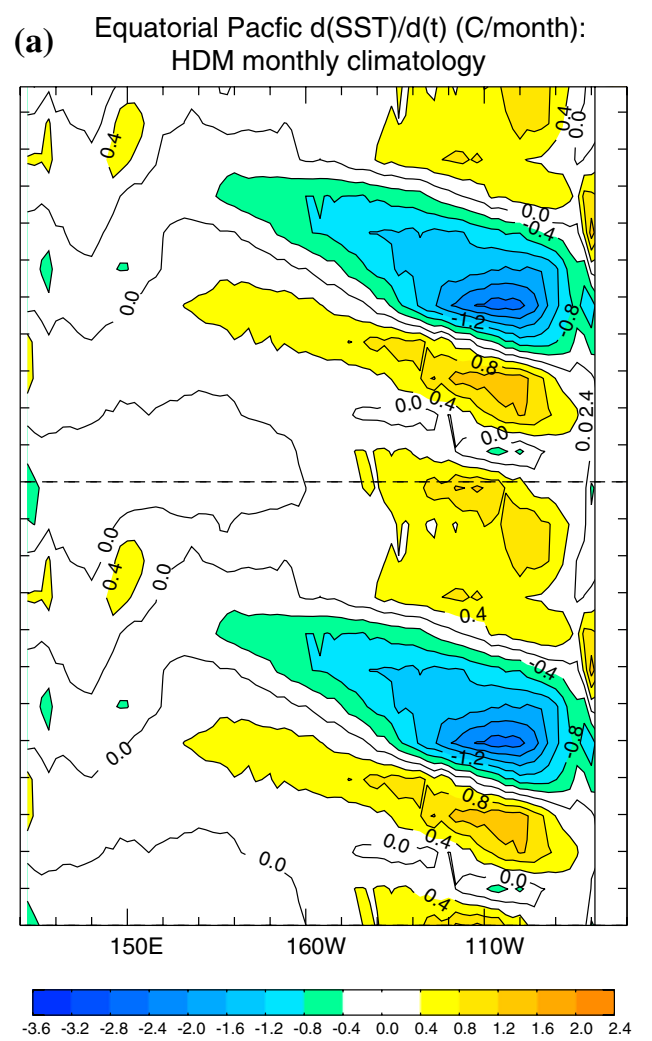

(b) Equatorial Pacific $\mathrm{d}(\mathrm{SST}) / \mathrm{d}(\mathrm{t})(\mathrm{C} /$ month):
HDC monthly climatology

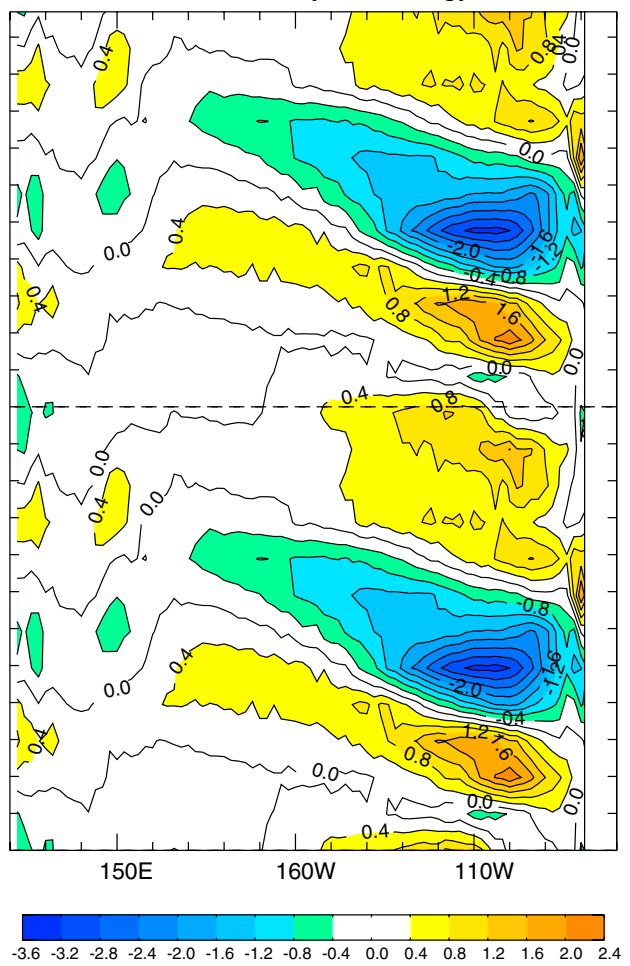

Fig. 7 The climatological monthly rate of change of SST along the equatorial Pacific for experiments HDM (a) and HDC (b)

propagation. This strong signal in the SST signature of the composites based on precipitation variability in HDC shows that the original hypothesis, that the stronger coupling implied by the inclusion of the diurnal cycle, is correct.

Other composites of the surface heat flux variability and wind stress (not shown) also show similar results to the precipitation and SST, that is, a stronger and a more coherent signature of the MJO is seen in HDC than in HDM across the tropical Indo-Pacific.

\section{Discussion and conclusions}

Many previous studies have examined the diurnal cycle in the atmosphere but the diurnal cycle of the upper ocean and

Table 1 Mean values of the MJO index defined by Slingo et al. (1999), in coupled simulations performed in this study

\begin{tabular}{lll}
\hline Data source & Data length (years) & Mean index \\
\hline HDM & 50 & 1.90 \\
HDC & 50 & 1.67 \\
ERA-40 & 20 & 2.31
\end{tabular}

Values for the ERA-40 reanalysis are also given for reference of ocean-atmosphere interaction has received little attention. The two parts of this study aimed to examine the role of the diurnal cycle of ocean-atmosphere coupling in the mean state and variability of the tropical climate. Of particular focus has been its role in the MJO due to the poor representation of the MJO in most CGCM and its dominance of tropical intraseasonal variability and interaction with other diverse climate phenomena such as the Monsoon and El Niño.

In the first part of this study (B07), a high vertical resolution (301 level) OGCM configuration with modified physics was configured to resolve the diurnal cycle in the upper ocean. The model was validated against in-situ and satellite data. It was then shown that the inclusion of the diurnal cycle and resulting Dsst lead to an increase in the intraseasonal SST response of the Indo-Pacific to the MJO of around $25 \%$, in line with the findings of the idealised 1-D mixed layer modelling study of Bernie et al. (2005). The inclusion of a properly resolved diurnal cycle also resulted in an increase in the strength of the Pacific sub-tropical cells by reducing the exchange of momentum between the equatorially divergent surface Ekmann layer and the equatorially convergent geostrophic currents at depth. Through its thermodynamical and dynamical effects the diurnal cycle in the upper ocean was proposed to have the potential 

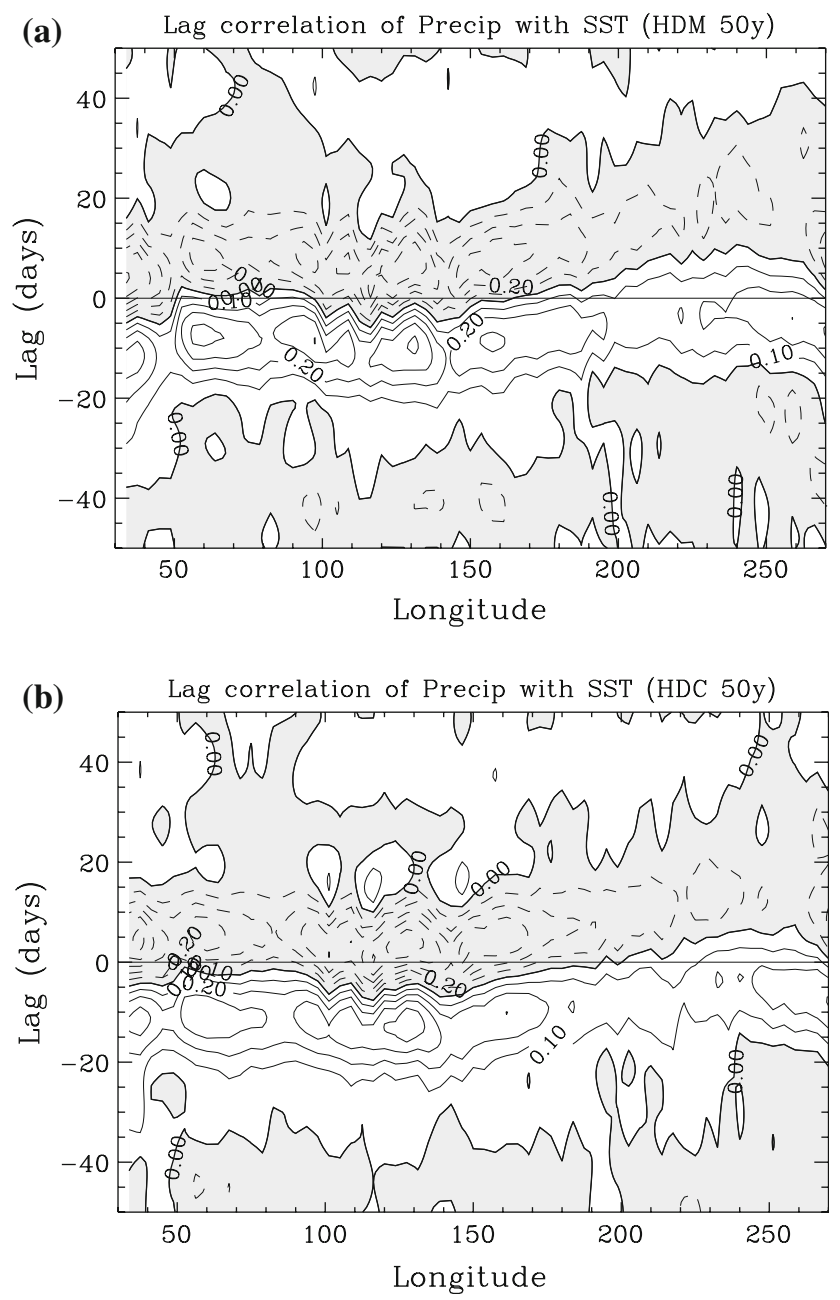

Fig. 8 Lag correlations between precipitation and SST. Negative lags indicate that the convection lags SST; positive lags indicate that the convection leads the surface fields. The sign convention is such that positive correlations indicate that enhanced precipitation is correlated with a negative SST anomaly. Negative correlations are shaded. Data is averaged between $10^{\circ} \mathrm{S}$ and $10^{\circ} \mathrm{N}$ for $\operatorname{HDM}(\mathbf{a})$ and $\mathrm{HDC}(\mathbf{b})$. These indicate a change in the timing between maxima in precipitation and SST by over 3 days

to produce systematic changes in the tropical climate however, such impacts could only be addressed in coupled ocean-atmosphere GCM experiments.

In the present paper the OGCM configuration developed in B07 was included in a CGCM. Two 50 year experiments were performed with the model using daily mean or 3 hourly coupling to assess the sensitivity of the tropical climate to inclusion of the diurnal cycle.

Sea surface temperature, a central variable for oceanatmosphere interaction, was found to have systematically warmer values across the equatorial pacific due to the rectification of the mean SST by a large mean Dsst which reached mean values of over $0.6^{\circ} \mathrm{C}$ in parts of the eastern Pacific. The equatorial warming of the Pacific lead to increased precipitation along the equator with an associated change in dynamical fields in the atmosphere. In the ocean there is an increase in the strength of subtropical cells due to the diurnal cycle, documented in the forced OGCM by B07, with stronger (10\%) equatorial upwelling and an increase in the surface equatorial divergence.

The thermodynamical and dynamical impacts of the diurnal cycle in the upper ocean where then found to combine in producing stronger basin scale ocean-atmosphere feedbacks on the seasonal cycle, leading to a stronger seasonal cycle of the coupled system in the eastern Pacific with a signal that then propagates west across the Pacific. Starting in boreal spring and moving through the seasonal cycle, once the ITCZ moves north away from the equator and the trade winds re-intensify, the stronger dynamical response of the upper ocean to the trade winds leads to a stronger and more rapid cooling of the cold tongue. The increased speed with which the cold tongue develops then leads to a more rapid development of the trade wind circulation. In addition to this, there is the role of Dsst. During the northern winter as the trades begin to drop in intensity (November to May) and the cold tongue warms, the presence of Dsst (Fig. 6d) increases the warming due to a rectification of the daily mean SST. Once the trades then start, the Dsst decreases and the daily mean SST drops accordingly also enhancing the seasonality of the system. This means that the diurnal cycle in the upper ocean plays a part in the coupled feedbacks between ocean and atmosphere that maintain the basic state and the timing of the seasonal cycle of the tropical Pacific.

The change in strength of the shallow meridional cells by changes in mixing characteristics has been discussed in several previous studies. For example Blanke and Delecluse (1993) show that the first order effect of a change in vertical mixing scheme in a tropical Atlantic OGCM is a change in the equatorial upwelling. Though the present study is not using a different mixing scheme in its sensitivity experiments, the way the vertical mixing is represented in terms of its temporal variability is altered and this essentially affects the vertical mixing of momentum which in turn effects the horizontal current structure and therefore the STCs, this time in the Pacific. Similarly Maes et al. (1997) show that the equatorial Pacific STCs adjust to changes in the prescribed lateral diffusion and so it is potentially not surprising that conversely changes in the vertical mixing lead to adjustment of the horizontal fields. However, the dynamical effect of the diurnal cycle has only had a small effect upon the seasonality of the coupled system considering that there is a relatively large change in the dynamical behaviour of the ocean. This is potentially a result of the relatively low atmospheric resolution inhibiting how well it can 'see' the ocean response (see discussion of Guilyardi 2006) as the surface signature of the dynamically controlled cold tongue has 

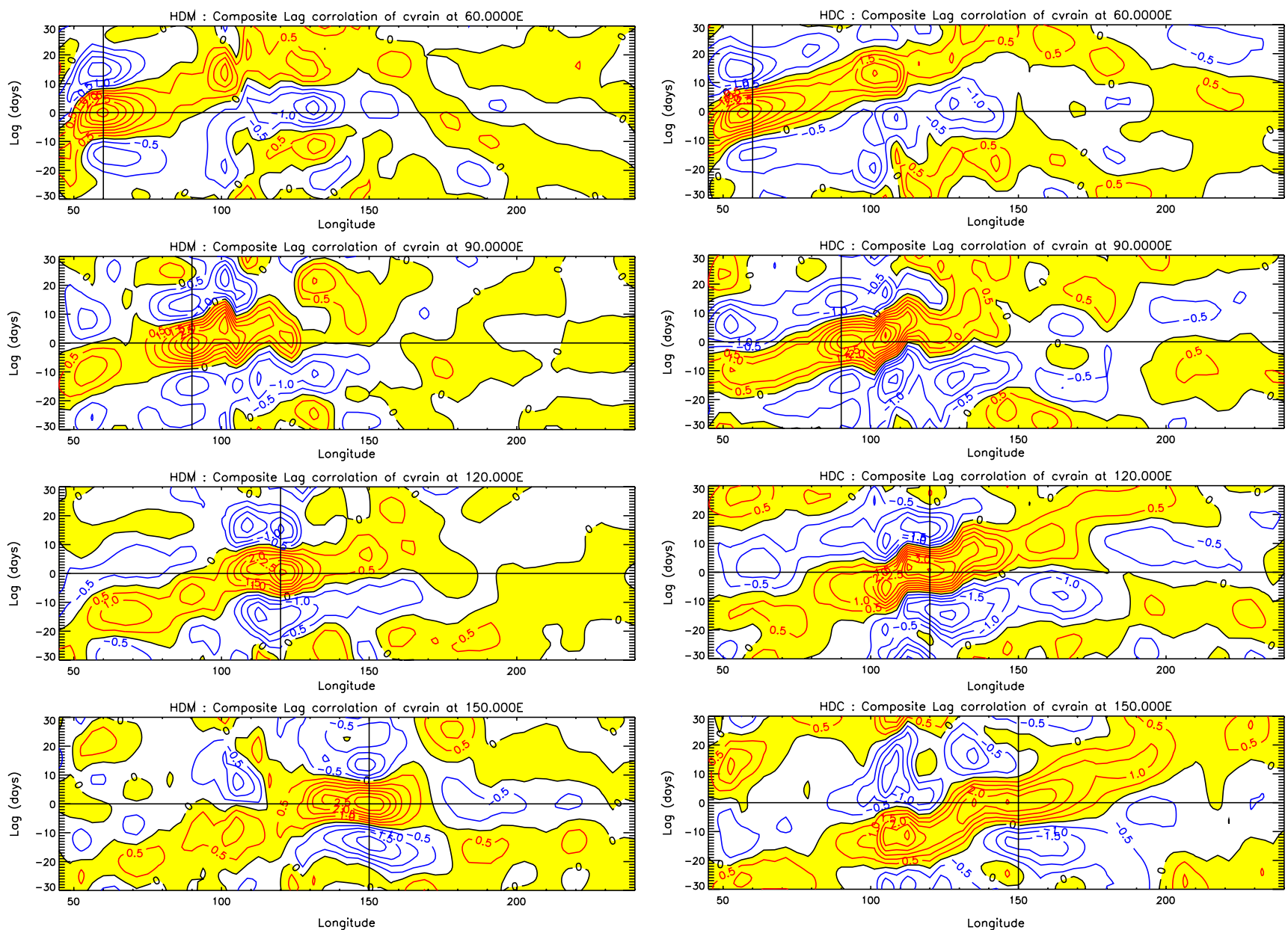

Fig. 9 Composites precipitation from MJO events identified from $10^{\circ} \mathrm{N}$ to $10^{\circ} \mathrm{S}$ mean $20-100$ day band pass filtered precipitation anomalies from 50 years of October to April output from HDM (left column) and HDC (right column). Composites are from lead and lag

only a small meridional extent and it is possible that the smoothing out of any change in this signature by the coarse atmospheric resolution used here is reducing the potential impact of the diurnal cycle.

Composites of the MJO are made for each simulation based on the variability of precipitation as a proxy for atmospheric convection. The precipitation composites show that the MJO is stronger and more coherent when the diurnal cycle of coupling is resolved, with the propagation and different phases being far more distinct both locally and to larger lead times across the tropical Indo-Pacific. The composites for SST based on precipitation variability show that the same is true of SST and crucially that the SST signal associated with the MJO is much stronger when the diurnal cycle of coupling is resolved in line with the results of part 1 of this study. This improvement in the structure of the MJO is supported by the lag correlations of precipitation with SST which show that the timing of the zero correlation line (the transition from correlation to anti-

times of \pm 30 days based at longitudes of $60,90,120$ and $150^{\circ} \mathrm{E}$ (from top to bottom) to represent the different phases of the MJO as it propagates from the Indian ocean, past the maritime continent out into the western Pacific warm pool

correlation) was shifted forward by an average of around 3 days across the Indo-Pacific consistent with the increase in the magnitude of the intraseasonal warming of SST in response to the MJO.

Overall these results imply that the inclusion of diurnal ocean-atmosphere interaction has both increased the strength of the coupling on the time scale of the MJO and made the MJO therefore more dependent on the coupling physics. However, the increased fidelity of ocean-atmosphere coupling, by inclusion of the diurnal cycle, has not proved to be a panacea for the MJO. Though the much improved coupling has improved the MJO, future improvements are more likely to come from developments in atmospheric model physics rather than further improvements in ocean-atmosphere coupling. For example the interaction of atmospheric convection and dynamics which has recently been shown to be poor in a number of atmospheric models (Yang et al. 2006; Lin et al. 2006). The importance of convective parameterisation is also 

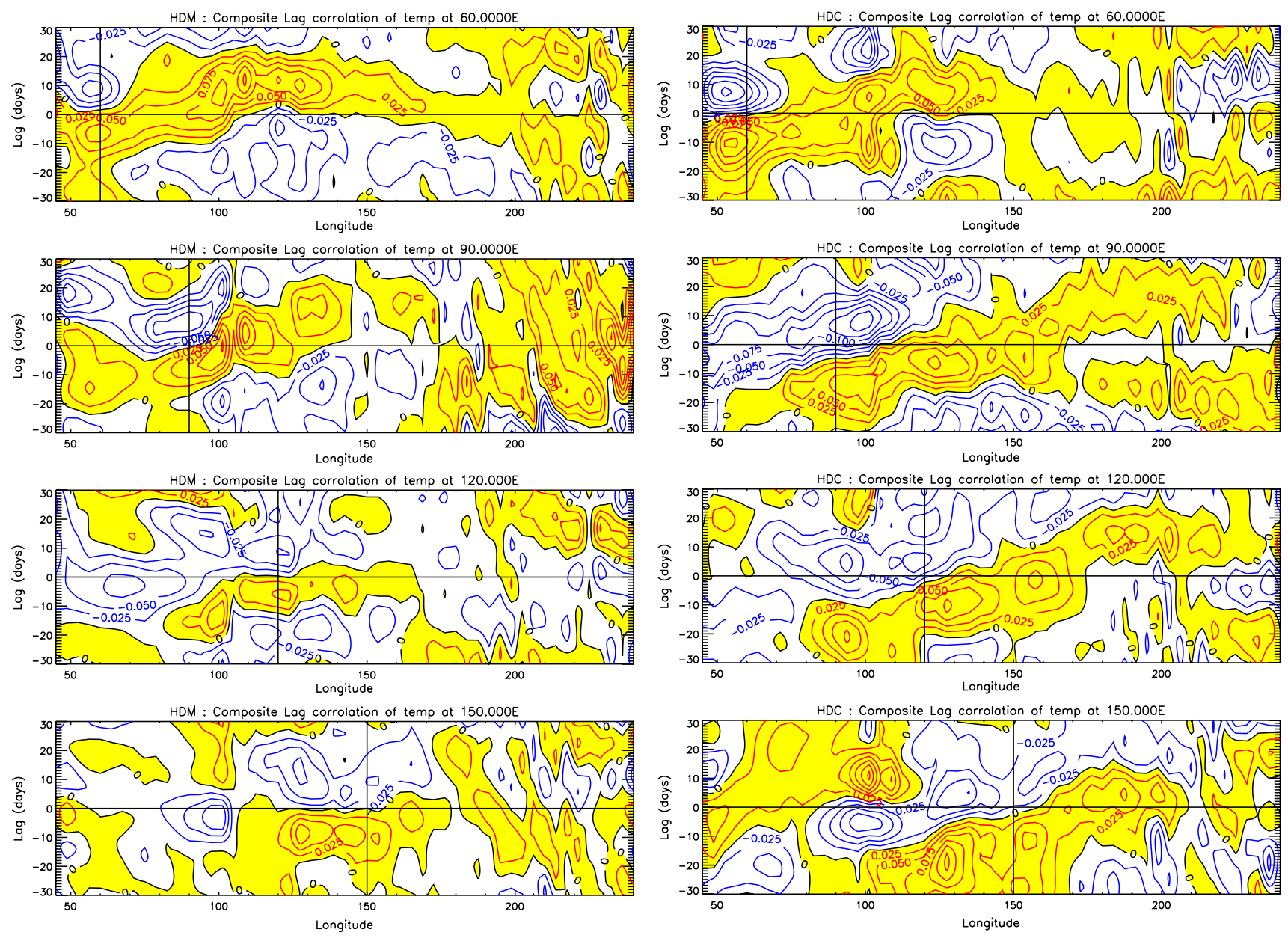

Fig. 10 As Fig. 9 but for SST based on precipitation variability

highlighted by Woolnough et al. (2007) who find no significant change in forecast skill of the MJO, using the ECMWF model, when Dsst is included. There is also the role of the diurnal cycle of shallow congestus during the suppressed phase of the MJO [c.f the recharge discharge hypothesis of Blade and Hartmann (1993)] highlighted in the introduction. Though the model used here has a higher vertical resolution to better resolve shallow congestus convection, there is no explicit representation of this population of clouds in this model and the diurnal cycle over the ocean has previously been shown to be poor in its diurnal phasing of convection (Yang and Slingo 2001). It is for these reasons that a study of the diurnal cycle of atmospheric convection driven by the Dsst was omitted in the present study. However this study has shown that the diurnal cycle of the upper ocean and ocean-atmosphere coupling is an important for the MJO.

There are a number of implications from this work for climate science and the future design of coupled models. From a scientific point of view diurnal coupling has been demonstrated for the first time to have a significant effect

on various aspects of the coupled system. The most ubiquitous feature, the diurnal variability of SST, has been shown to enhance the SST response to the MJO and therefore increase the effective strength of air-sea coupling leading to more coherent and structured MJO. It has also been demonstrated that the diurnal variability of momentum mixing in the ocean has a basin scale impact on the dynamics of the tropical pacific which, combined with diurnal SST variability, are involved in strengthening the coupled feedbacks in the Pacific sector thereby enhancing its seasonality. As a result of the demonstrated sensitivity of CGCM it is strongly recommended that the diurnal cycle of ocean atmosphere coupling should be included in future climate model development.

Acknowledgments The authors are grateful for helpful discussions with Rowan Sutton, Pascale Delecluse, Arnaud Caubel and Matthieu Lengaigne. D. Bernie and S. Woolnough acknowledge the Natural Environment Research Council's support through grant NER/A/S/ 2000/1283. All simulations were performed on the NEC SX-6 supercomputer at the German Climate Computing Centre (DKRZ) in Hamburg. 


\section{References}

Anderson SP, Weller RA, Lukas RB (1996) Surface buoyancy forcing and the mixed layer of the western Pacific warm pool: observations and 1D model results. J Clim 9:3056-3085

Annamalai H, Slingo JM (2001) Active/break cycles: diagnosis of the intraseasonal variability of the asian summer monsoon. Clim Dyn 18:85-102

Bernie DJ (2006) Diurnal variability of the tropical upper ocean and its climate impacts. PhD Thesis, Department of Meteorology, University of Reading, Available at http://www.metnt.rdg.ac.uk/ Scripts/Library/PHDTheses.asp

Bernie DJ, Woolnough SJ, Slingo JM, Guilyardi E (2005) Modelling diurnal and intraseasonal variability of the ocean mixed layer. J Clim 15:1190-1202

Bernie DJ, Guilyardi E, Madec G, Woolnough SJ, Slingo JM (2007) Impact of resolving the diurnal cycle in an ocean-atmosphere GCM. Part 1: Diurnally forced OGCM. Clim Dyn 29:575-590

Bjerknes J (1969) Atmospheric teleconnections from the equatorial Pacific. Mon Wea Rev 97:163-172

Blade I, Hartmann DL (1993) Tropical intraseasonal oscillations in a simple model. J Atmos Sci 50:2922-2939

Blanke B, Delecluse P (1993) Variability of the tropical Atlantic ocean simulated by a general circulation model with two different mixed-layer physics. J Phys Oceanogr 23:1363-1388

Chapman WL, Walsh JE (1991) Long-range prediction of regional sea ice anomalies in the arctic. Weather Forecasting 6:271288

Cox P, Betts RA, Bunton C, Essery R, Rowntree PR, Smith J (1999) The impact of new land surface physics on the $\mathrm{gcm}$ simulation of climate and climate sensitivity. Clim Dyn 15:183-203. doi: $10.1007 / \mathrm{s} 003820050276$

Danabasoglu G, Large WG, Tribbia JJ, Gent PR, Briegleb BP, Mc Williams JC (2006) Diurnal coupling in the tropical oceans of CCSM3. J Clim 19:2347-2365

Davey MK, co-authors (2002) STOIC: a study of coupled model climatology and variability in tropical ocean regions. Clim Dyn $18: 403-420$

Fairall CW, Bradley EF, Hare JE, Grachev AA, Edson JB (2003) Bulk parmameterisation of air-sea fluxes: updates and verification for the COARE algorithm. J Clim 16:571-591

Gates WL, Boyle J, Covey C, Dease C, Doutriaux C, Drach R, Fiorino M, Gleckler P, Hnilo J, Marlais S, Phillips T, Potter G, Santer B, Sperber K, Taylor K, Williams D (1998) An overview of the results of the atmospheric model intercomparison project (amip i). Bull Am Meteor Soc 73:1962-1970

Gent PR, McWilliams JC (1990) Isopycnal mixing in ocean circulation models. J Phys Oceanogr 20:150-155 (notes and correspondence)

Gregory D, Rowntree PR (1990) A mass flux convection scheme with representation of cloud ensemble characteristics and stability dependent closure. Mon Wea Rev 118:1483-1506

Griffies SM, Gnanadesikan A, Dixon KW, Dunne JP, Gerdes R, Harrison MJ, Rosati A, Russell JL, Samuels BL, Spelman MJ, Winton M, Zhang R (2005) Formulation of an ocean model for global. Ocean Sci 1:45-79

Guilyardi E (2006) El niño-mean state-seasonal cycle interactions in a multi-model ensemble. Clim Dyn 26:329-348

Hendon HH, Glick J (1997) Intraseasonal air-sea interaction in the tropical indian and pacific oceans. J Clim 10: 647-661

Hendon HH, Salby ML (1994) The life cycle of the Madden-Julian Oscillation. J Atmos Sci 51:2225-2237

Inness PM, Slingo JM (2003) Simulation of Madden-Julian oscillation in a coupled general circulation model. Part 1: Comparison with observations and an atmosphere-only GCM. J Clim 16:345-364
Inness PM, Slingo JM, Woolnough SJ, Neale RB, Pope VD (2001) Organisation of tropical convection in a GCM with varying vertical resolution; implications for the simulation of the Madden-Julian Oscillation. Clim Dyn 17:777-793

Inness PM, Slingo JM, Guilyardi E, Cole J (2003) Simulation of Madden-Julian oscillation in a coupled general circulation model. Part 2: The role of the basic state. J Clim 16:365-384

Johnson RH, Rickenbach TM, Rutledge SA, Ciesielski PE, Schubert WH (1999) Trimodal characteristics of troical convection. J Clim 12:2397-2418

Kessler WS, Kleeman R (2000) Rectification of the Madden-Julian oscillation into the ENSO cycle. J Clim 13:3560-3575

LAU K-M, Xiaofan L, WU H (2002) Evolution of the large scale circulation, cloud structure and regional water cycle associated with the south China sea monsoon during May-June, 1998. J Meteor Soc Japan 80:1129-1147

Lawrence DM, Webster PJ (2001) Interannual variations of the intraseasonal oscillation in the south Asian summer monsoon region. J Clim 14:2910-2922

Lengaigne M, Madec G, Menkes C, Alory G (2003) Impact of isopycnal mixing on the tropical ocean circulation. J Geophys Res 108:3345-3359

Lengaigne M, Guilyardi E, Boulanger J-P, Menkes C, Inness P, Delecluse P, Slingo JM (2004) Coupled mechanisms involved in the triggering of el nińo by a westerly wind event. Clim Dyn 23:601-620. doi:10.1007/s00382-004-0457-2

Lin J-L, Kiladis G, Mapes B, Weickmann KM, Sperber KR, Lin W, Wheeler MC, Schubert SD, Genio AD, Donner LJ, Emori S, Gueremy J-F, Hourdin F, Rasch PJ, Roeckner E, Scinocca JF (2006) Tropical intraseasonal variability in 14 IPCC AR4 climate models. Part I: Convective signals. J Clim 19:2665-2690

Madec G, Delecluse P, Crepon M, Chartier M (1991) A threedimensional numerical study of deep-water formation in the northwestern mediterranean sea. J Phys Oceanogr 21:13491371

Madec G, Delecluse P, Imbard M, Lévy C (1998) OPA 8.1 Ocean General Circulation Model reference manual. Institut PierreSimon Laplace (IPSL), France, no 11 edition

Maes C, Madec G, Delecluse P (1997) Sensitivity of an equatorial Pacific OGCM to the lateral diffusion. Mon Wea Rev 125:958-971

McPhaden MJ (1999) Genesis and evolution of the 1997-98 El Niño. Science 283:950-954

Mechoso CR, co-authors (1995) The seasonal cycle over the tropical pacific in coupled ocean-atmosphere general circulation models. Mon Wea Rev 123:2825-2838

Mellor G, Blumberg A (2004) Wave breaking and ocean surface layer thermal responce. J Phys Oceanogr 34:693-698 (notes and Correspondants)

Nakazawa T (1988) Tropical super clusters within intraseasonal variations over the western Pacific. J Meteor Soc Japan 66:823839

Pope VD, Pamment JA, Jackson DR, Slingo A (2001) The representation of water vapour and its dependence on vertical resolution in the Hadley Centre Climate Model. J Clim 14:3065-3085

Rajendran K, Kitoh A (2006) Modulation of tropical intraseasonal oscillations by ocean-atmosphere coupling. J Clim 19:366-391

Roullet G, Madec G (2000) Salt conservation, free surface, and varying levels: a new formulation for ocean general circulation models. J Geophys Res 105:23,927-23,942

Shinoda T, Hendon HH (1998) Mixed layer modeling of intraseasonal variability in the tropical western Pacific and Indian oceans. J Clim 11:2668-2685

Shinoda T, Hendon HH, Glick J (1998) Intraseasonal variability of surface fluxes and sea surface temperatures in the tropical western Pacific and Indian oceans. J Clim 11:1685-1702 
Simmons AJ, Gibson JK (2000) The ERA-40 project plan. ERA-40 Project Rep. Technical report, European Centre for Medium Range Weather Forcasting

Slingo JM, co-authors (1996) Intraseasonal oscillations in 15 atmospheric general circulation models: results from an AMIP diagnostic subproject. Clim Dyn 12:325-357

Slingo JM, Rowell DP, Sperber KR, Nortley F (1999) On the predictability of the interannual behaviour of the Madden-Julian oscillation and its relationship with El Niño. Ouart J Roy Meteor Soc 125:583-609

Slingo JM, Inness P, Neale R, Woolnough S, Yang G-Y (2003) Scale interactions on diurnal to seasonal timescales and their relevance to model systematic errors. Ann Geophys 46:139-155

Slingo J, Molteni F, Moncrieff M, Shapiro M (2006) Organisation and maintenance of tropical convection and the madden julian oscillation. THORPEX/WCRP/ICTP

Valcke S, Caubel A, Vogelsang R, Declat D (2004) Oasis3 user's guide prism 2-4, 5th edn. Technical report, CERFACS, Toulouse, France, pRISM Report Series No 2

Waliser DE, Lau KM, Kim J-H (1999) The influence of coupled sea surface temperatures on the Madden-Julian oscillation: a model pertubation experiment. J Atmos Sci 56:333-357

Webster PJ, Lukas R (1992) TOGA COARE: the coupled oceanatmosphere response experiment. Bull Am Meteor Soc 73:13771416
Woolnough SJ, Slingo JM, Hoskins BJ (2000) The relationship between convection and sea surface temperature on intraseasonal timescales. J Clim 13:2086-2104

Woolnough SJ, Slingo JM, Hoskins BJ (2001) The organization of tropical convection by intraseasonal sea surface temperature anomolies. Quart J Roy Meteor Soc 127:887-907

Woolnough SJ, Vitart F, Balmaseda MA (2007) The role of the ocean in the Madden-Julian Oscillation: implications for mjo prediction. Q J R Meteorol Soc 133:117-128

Xie P, Arkin PA (1996) Analyses of global monthly precipitation using gauge observations, satellite estimates, and numerical model predictions. J Clim 9:840-858

Yang G, Slingo JM (2001) The diurnal cycle in the tropics. Mon Weath Rev 129:784-801

Yang G, Hoskins B, Slingo J (2006) Convectively coupled equatorial waves. Part III: Synthesis structures and their forcing and evolution. J Atmos Sci (submitted)

Zhang C, Dong M, Gualdi S, Hendon H, Maloney ED, Marshall A, Sperber K, Wang W (2006) Simulations id the Madden-Julian oscillation in four pairs of coupled and uncoupled global models. Clim Dyn, online first 